\title{
Proceeding
}

Supplementary Issue: Spring Conferences of Sports Science. Costa Blanca Sports Science Week, 26-28 April 2018. Calpe. Alicante, Spain

\section{Physical activity and sports sciences between European Research Council and academic disciplines in Italy}

\author{
GAETANO RAIOLA ${ }^{1} \triangle$, FRANCESCA D'ELIA ${ }^{1}$, GAETANO ALTAVILLA ${ }^{2}$ \\ ${ }^{1}$ Department of Human, Philosophical and Education Sciences, University of Salerno, Italy \\ ${ }^{2}$ Faculty of Kinesiology, University of Split, Croatia
}

\begin{abstract}
Also in Italy, as well as to be in all others states European Union, the academic disciplines in university system have to change to conform to the 3 areas: SH Social Sciences and Humanities, PE Physical Sciences and Engineering, LS (Life Sciences), 25 panel and 333 sub panel of European Research Council Panel Structure 2018. Nowadays, it is compulsory to have the same language within the European Union and its European Research Council Executive Agency (ERCEA). This change concerns the funding of research and the recruitment of professors; currently in Italy they follow two different procedures and the reform aims to pursue the unique way. Physical activity and sports sciences are in two different scientific areas: the human and social sciences and the life sciences. The problem is therefore to choose a single scientific area or to stay in two areas, to define the declaration of the academic discipline with the protection of the professors' rights and the relationship with the ERC Area. The academic disciplines of Physical activity and Sport sciences field could be made by the following descriptors: Health, ageing - Social aspects of learning, curriculum studies, educational policies - Science and technology studies - Cognitive basis of human development and education, developmental disorders; comparative cognition - Personality and social cognition - Emotion - Clinical and health psychology - Neuropsychology - Attention, perception, action, consciousness - Learning, memory - Cognition in ageing - Reasoning, decision-making - Intelligence Language learning and processing - Theoretical linguistics - computational linguistics - Comparative physiology and pathophysiology - Fundamental mechanisms underlying ageing - Sensation and perception - Neural bases of cognitive processes - Other medical technologies for diagnosis and monitoring of diseases

Corresponding author. Department of Human, Philosophical and Education Sciences, University of Salerno, Italy. http://orcid.org/0000-0002-7659-1674

E-mail: raiolagaetano@libero.it

Supplementary Issue: Spring Conferences of Sports Science. Costa Blanca Sports Science Week, 26-28 April 2018. Calpe. Alicante, Spain.

JOURNAL OF HUMAN SPORT \& EXERCISE ISSN 1988-5202

(c) Faculty of Education. University of Alicante

doi: 10.14198/jhse.2018.13.Proc2.13
\end{abstract}


- Epidemiology and public health - Environmental health, occupational medicine - Health services, health care research, medical ethics. In Italy its declaratory could be simplified: "Theories and methods of physical education, training, health and well-being" in Life sciences area with the exception for some professors to be structured in human and social sciences for educational profile. Key words: TRAINING, EDUCATION, PERFORMANCE, ACADEMIC DISCIPLINES, DESCRIPTORS.

\section{Cite this article as:}

Raiola, G., D'Elia, F., \& Altavilla, G. (2018). Physical activity and sports sciences between European research council and academic disciplines in Italy. Journal of Human Sport and Exercise, 13(2proc), S283-S295. doi:https://doi.org/10.14198/jhse.2018.13.Proc2.13 


\section{INTRODUCTION}

Currently the Italian university system discusses its transformation to respond to the request for alignment of the model used in the scientific world, particularly European Union. The Italian Government, through the Ministry of Education, University and Research (MIUR), must reorganize the Research and Training System in order to interact effectively with the international research context for the organizational, financial and economic aspects. The debate inside the academy is all about the real necessity and the reduced times of the process of change. The utilization of the European Research Council model by the Executive Agency appointed by the European Commission with the aim of unifying research fields and methods at European level has alarmed the most conservative part of the university system. The current system of knowledge has three hierarchical levels: the academic scientific disciplinary, the academic recruitment field and group of academic recruitment field (attachment D DM 355, 2015) in each of the 14 scientific areas of the rearranged National University Council (CUN law 18, 2006); this organizational structure has the purpose of evaluating research, the teaching organization and national scientific qualification and recruiting of the professors. This classification of academic disciplines is very wide but little correspond to the European Research Council Panel Structure ERC-Panel Structure (https://erc.europa.eu/sites/defaultfiles/documentfile/ERC_Panel_structure_2018.pdf) model with the difficulty of evaluating Italian research projects at the European level. Therefore the urgent and unavoidable adjustment is in conflict with the interests of that part of university system who have the convenience to maintain the current academic asset and governance. The adaptation to the European rules would have a strong impact in Italy that historically has its own research modalities in the area of human and social sciences, modalities of publications only with monographs, chapters in book and articles not indexed by the traditional databases (Web of Science and Scopus). In addition, academic disciplines is structured in an atypical way compared to that of other European countries that need, in addition to the appropriate equivalences between the academic positions of Italian professors with those foreign, also of the collocation corresponding in the fields of academic disciplines. The main case is that of the physical activity and sports sciences that sees the current arrangement with a typical Italian solution that, not satisfying anyone, sees the division into two different scientific areas with opposing traditions and research methods: the didacticeducational part in an area so-called non-bibliometric and the bio-medical area located in a bibliometric area both for evaluating scientific products. This involves a scientific ubiquity with difficulties of assessing research, of the training and didactic organization and of recruitment and of career progression of university professors and researchers. Regardless of this problem, the physical activity and sport sciences field presents the needs for stabilization and simplification in an only area of scientific identity and place in the academic system, so it has an unique evaluation of scientific products. From the quantitative point of view, that is the numerosity of the professor of physical activity and sports sciences, it should be noted that most of the teachers are structured on bio-medical area and therefore the problem of the criticality of the reduced number of professors that they have lines of research in physical education and sports worsen the situation. Moreover, this anomaly is also found in the different translations that the titling of the academic disciplines of the physical activity and sports sciences field has in the contents of ministerial documents; the two academic disciples are differently titled in English tongue according to whether they are in biomedical area or social and humanistic area. The titling of the sectors Methods and teaching of motor activities and Methods and teaching of sports activities in 06N2-Physical training and sport sciences is: PHYSICAL TRAINING AND SPORTS SCIENCES M-EDF/01 - PHYSICAL TRAINING SCIENCES AND METHODOLOGY M-EDF/O2 - SPORT SCIENCES AND METHODOLOGY and in 11d2-Methodologies of teaching, special education and educational research is METHODOLOGIES OF TEACHING, SPECIAL EDUCATION AND EDUCATIONAL RESEARCH M-EDF/01 - METHODS AND TEACHING OF MOTOR ACTIVITIES M-EDF/O2 - METHODS AND TEACHING OF SPORTS ACTIVITIES (attachment D DM 355, 2015). So the opportunity for the rearrangement and 
simplification of academic disciples is an opportunity to solve the problem exposed. The purpose of this study is to trace the logical documentation process of the evolution of physical activity and sports sciences through the consultation of all official documents, also with a historical approach to identify exactly the temporal location. To retrace the essential steps from the normative genesis of sports motor knowledge, starting from the institutive law of the Higher Institutes of Physical Education of 1958 (law n. 88 Institution of the ISEF, 1958), to reach the current topical point of transformation of the structure of the disciplinary scientific sectors in line with the European Commission requests related to the European Research Conuncil (ERC). To immediately place the topic of the study in the context of general reference, we need a summary of the most important facts that can achieve the goal: to outline the complex problematic with a linearly logical path, obtained through the analysis and applications of documents. For the short period of time taken into consideration, consisting of the sub-period 1958-1998, life of the Higher Institutes of Physical Education ISEF, to everything today and for the strong documentary significance of the changing, it is difficult to calibrate the level right degree of simplification due to the stratification of the measures taken to cope with the emergencies of the university system.

\section{Short historical excursus from the Second World War to the first post-war period}

To introduce the study it is necessary to start from a synthesis of the state of the art of the organizational structure, which is centralized, of the University with respect to the common exception that derives from the principle of university autonomy. The second after war was a dark period for physical and sports education because there was an intense and long political reaction, totally replaced with respect to the previous regime. The physical and moral exaltation of the race, contained in the racial laws of the Kingdom of Italy extended to all possible fields including that of motor and sports sciences, beyond as an instrument of military offense and of social and cultural segregation, was also a significant element which had also permeated layers of the society. The issue of physicality, performance and physical beauty linked to physical exercise had strongly deluded public opinion to such an extent that it did not suggest that this exaltation had contributed to bring in Italy to the brink of social abyss. With the change of regime and the consequent new political class, the concern of a return to the drifts of the past grew due to the fascination that the theme of a strong and vigorous body could still provoke (Raiola, 2017). The new state apparatus, constituted in the new republican form, therefore relegated the physical and sports sciences to limbo waiting for better times with the conviction to remove the past conditioning and at the same time to reduce the understandable reactions to the disaster caused by the previous politics. Thus began a period of absolute inertia, which lasted 13 years, in which it was decided to rebuild the physical and sport education within the education and university without having however in any consideration the contribution that a physical education and culturally renewed sport could and should give. Everything was suspended and only in the elementary schools with the Ermini programs in 1955 there was a timid presence of the physical activity even if it debased its specific and educational contents. In the other grades of schools' physical education was left to a state of total abandonment because it was entrusted to personnel unqualified, coming from other professions, through a direct call recruitment that did not provide any training at all. In 1958, thanks to the political acumen of the then Minister of Education, Aldo Moro, the physical education discipline in secondary school was stabilized, the organic role of the teachers of Physical Education PE was constituted and, years after the abolition of the Academies of Rome and Orvieto, were instituted the Higher Institutes of Physical Education with the task of training the PE teachers. At the same time, on the sporting side the institutional political apparatus initiated the same action of reaction to the physical and moral exaltation of the race, appointing the liquidator commissioner of the Italian National Olympic Committee (CONI), a body endowed with legal personality. However, he did not comply with the mandate given to him and made the CONI reborn, depleting it of those principles and mechanisms characterizing the fascist period and consolidating its organizational and managerial aspects. The CONI became, in addition that the Confederation of sports federations, also a real body in substitution 
of the State with tasks of development of sport and financed with the proceeds deriving from the State. Promoted the establishment of new national sports federations, strengthened the existing ones, instituted the Sports Promotion and was hierarchically structured with a self-sufficient regulation that ensured its complete autonomy from political power. It replaced the State in the training of sports technicians, built and ran sports facilities and slowly with a progressive collaboration began to be an indispensable partner for the School. The Youth Games, the Student Championships and the special projects for motor education in the Primary school were carried out, completely replacing the State with the title of education for movement and sport (D'Elia, Raiola, 2018). From time CONI projects: Physical literacy and Sport class are the basis of physical, motor and sports education in the Primary school. The act of birth of physical activity and sport sciences in Italy after the Second World War was the law that established the Higher Institutes of Physical Education. The law n. 88 of 7 February 1958, in Title III article 22 et seq., Instituted the higher institutes of Physical Education of university degree with the issuing of the academic degree of the diploma instead of the degree considered the triennially of the course of study. The institutes (11) were equalized to the only public, the one already existing in Rome, the only one that had specific funding from the state and that also subsequently retained the prerogative of a leading academic venue for physical activity and sports sciences. As a result of the equalization, the ISEF issued three-year academic qualifications with legal value, called a diploma to distinguish them from the degree that at the time generally had a four-year course of study while having the same legal weight.

\section{The recent history: From the ISEF Reformation to today}

Cotemporally to declare the new documents of PE (Gaetano, 2012) and with regard to the discussion of the issue, the documentary path is to start with the observation that, after many failed legislative attempts related to the reform of the ISEFs, only at the end of the last century (after more than 40 years from the ISEF institutive law), the government issued the Legislative Decree 8 May 1998, n. 178 "Transformation of Higher Institutes of Physical Education and Establishment of Faculties and Degree and Diploma Programs in physical activity and sports sciences, in accordance with the article 17, comma 115 of law Bassanini bis the (Law 127, 1997). Thus the two new disciplinary scientific sectors are established, the field of the motor activity sciences, the field of sports sciences.

Table 1. Academic disciplines of physical activity and of sports sciences

\section{Academic disciplines}

1) Sciences of physical activities: a) Theory and methodology of human movement; b) Theory, technique and didactic of motor activity for the developmental age; c) Theory, technique and didactic of motor activities for adulthood and elderly; d) Theory, technique and didactic of group activities, recreational and free time; e) Theory, technique and didactic of "adapted" motor and sport activities; f) Theory, technique and didactic of preventive and compensative motor education.

2) Sports Sciences: a) Theory and methodology of training; b) Theory, technique and didactic of individual sports; c) Theory, technique and didactic of team sports; d) Theory, technique and didactic of swimming sports; e) Methods of motor assessment and aptitudinal in sport; f) Organization of the sport organisms.

The law n. 240 of 30 December 2010 defined the academic recruitment field and group of academic recruitment field aggregating the academic disciples, so the Ministerial Decree no. 336 of 29 July (2011), determination of the academic recruitment field and group of academic recruitment field aggregating the academic disciples, detailing the contents with specific declaratory concorsuals. The National University Council, technical organism of the minister in university subject, has expressed specific technical declarations and specifically the physical activity and sports sciences were placed in academic recruitment field and group of academic recruitment field according to the following scheme: 
Table 2. Group of academic recruitment field and academic recruitment field

Group of academic recruitment field and academic recruitment field

05/D - Group of academic recruitment field PHYSIOLOGY 05 / D1: PHYSIOLOGY The sector is interested in the scientific and didactic-training activities .... Evaluate ..., the expenditure and energy needs, ... Analyse and evaluate the integrated functioning of the various organs and systems during motor and sport activities and in extreme environmental conditions.

05/E - Group of academic recruitment field - Biochemistry and Molecular Biology EXPERIMENTAL AND CLINICAL academic recruitment field 05 / E1: Biochemistry General and Clinical Biochemistry. The sector is interested in scientific and educational-training activities .... Clinical Biochemistry and Clinical Molecular Biology study ... structural and dynamical biochemical parameters relevant in the ... field of motor and sport activities.

05/F - Group of academic recruitment field - APPLIED BIOLOGY academic recruitment field 05 / F1: APPLIED BIOLOGY .... The sector also studies the cellular bases of motor activity, behaviour and evolution....

05/H - Group of academic recruitment field - HUMAN ANATOMY AND HISTOLOGY academic recruitment field 05 / H1 Human Anatomy and Histology ... studied anatomical knowledge applied .... of interest ... and of the sports sciences, of the movement and of the maintenance of the state of health.

05/L - Group of academic recruitment field - SCIENCES OF THE PHYSICAL EXERCISE AND SPORT academic recruitment field 05 / L1: SCIENCES OF PHYSICAL EXERCISE AND SPORT. The sector is interested in the scientific and didactic-training activity in the biochemical, biological, morphological and physiological fields of the development of theories, techniques and methods for the training and practice of different sports activities and assessments of athletic performances and attitudes.

06/B - Group of academic recruitment field - GENERAL MEDICAL CLINIC academic recruitment field 06 / B1: INTERNAL MEDICINE ... The sector also has specific competence ... in the medicine of exercise and sport,...

06/D - Group of academic recruitment field - SPECIALISTIC MEDICAL CLINIC academic recruitment field 06 / D2: ENDOCRINOLOGY, NEPHOLOGY AND FOOD SCIENCE AND WELLNESS Areas of expertise are ... the pathophysiology and clinical ... of exercise and sport; ...

06/N - Group of academic recruitment field - SANITARY PROFESSIONS AND APPLIED MEDICAL TECHNOLOGIES academic recruitment field 06 / N1: SCIENCES OF HEALTH PROFESSIONS AND APPLIED MEDICAL TECHNOLOGIES....

Subsequently, it occurs a rearrangement of academic disciples in Group of academic recruitment field and academic recruitment field (law 114, 2014). The academic disciplines is also interested in the scientific and training didactic activity in the field of Technique and Clinical physical exercise and sports with particular regard to physical education and general physical activity and addressed to particular groups of people or age groups, to clinical studies for the development of theories, techniques and methods for the training and practice of different sports activities and evaluations of athletic performances and attitudes and the organization and professional management of physical education and training... Subsequently, as a result of the modify of the CUN expressed the prescribed opinion that placed the physical activity and sports sciences in only Group of academic recruitment field and academic recruitment field and so in the Ministerial Decree 855 of 30 October 2015 appeared only 2 competition declaratory:

1. 06/N2: PHYSICAL EXERCISE AND SPORT SCIENCES. The academic recruitment field is interested in the scientific and didactic-training activity in the biochemical, biological, morphological, physiological and clinical fields related to the development of theories, techniques and methods for training and for the practice of different sports and motor activities and evaluations of performances 
and athletic attitudes. Moreover, the academic recruitment field is interested in the scientific and didactic-training activity in the field of technical and clinical of physical exercise, physical activity and sports with particular regard to motor and physical education (both general and aimed at particular groups or classes of age) and of the evaluations of the effects of the physical activity also through bio-humoral and clinical parameters for the achievement of the well-being and health, of the performances and of the athletic attitudes. Finally, the academic recruitment field deals with the organization and professional and health management of physical education and training, the educational goals of physical and sport activities and the related teaching-learning processes, in formal and informal contexts that support them.

2. 11 / D2: DIDACTICS, SPECIAL PEDAGOGY AND EDUCATIONAL RESEARCH The academic recruitment field is interested in scientific and didactic-training activities .... In particular, it deals with research on issues of ... education to physical and sports activities.

The CUN has to simplify the complexity of the academic organization of the academic disciplines and the academic recruitment field elaborated a series of keywords to have a tool of declination of specific knowledge simpler and at the same time wider to better define and accurately scientific issues. The CUN Opinion of 28 September (2016) "Proposal of a list of key words, in Italian and English, on the scientific-disciplinary indicators useful for identifying the profile. Proposal of a list of keywords, in Italian and English, concerning the scientific disciplinary indicators useful for identifying the scientific profile of researchers "(Informa CUN $225,2018)$. From the list of the 2400 key words developed by the CUN, those linked to the essence of motor and sports knowledge were chosen. Moreover, from the list have been chosen those related ones in a logic of close link with the essential ones and limited to elaborations which are extremely pertinent and coherent to the transversal logic of knowledge. They are with an alphabetical number in the Italian language.

Table 3.10 CUN Keywords

\begin{tabular}{|l|c|}
\hline \multicolumn{2}{|c|}{ 10 CUN KEYWORDS related to physical activity and sport } \\
\hline 35 & Physical training \\
\hline 225 & Biomechanics \\
\hline 501 & Human movement and sport education \\
\hline 710 & Ergonomics \\
\hline 845 & Fitness \\
\hline 1335 & Sport medicine \\
\hline 1616 & Sport pedagogy \\
\hline 1784 & Sport psychology \\
\hline 1933 & Physical training and sport sciences \\
\hline 2253 & Movement development \\
\hline
\end{tabular}


Table 4. 20 CUN Keywords

\begin{tabular}{|c|c|}
\hline \multicolumn{2}{|c|}{20 CUN KEYWORDS near to physical activity and sport } \\
\hline 33 & Nutrition \\
\hline 109 & Learning \\
\hline 201 & General biochemistry and metabolism \\
\hline 351 & Spatial cognition \\
\hline 376 & Communication and visual perception \\
\hline 461 & Decision making \\
\hline 490 & Didactic \\
\hline 550 & Sport law \\
\hline 593 & Disability \\
\hline 608 & Docimology \\
\hline 653 & Education \\
\hline 705 & Epistemology \\
\hline 835 & Muscle physiology \\
\hline 837 & Nutrition physiology \\
\hline 858 & Teachers education \\
\hline 1066 & Social inclusion \\
\hline 1140 & Integration \\
\hline 1381 & Learning sciences \\
\hline 1932 & Educational systems \\
\hline 1992 & \\
\hline
\end{tabular}

Understanding the new system is essential. The basis on which to develop the reflections is the recent document of the composition of the scientific areas of the classification of "knowledge" as defined at the European headquarters by the body in charge. This document is composed of 3 main areas: Social and Humanities Sciences, Physical Sciences and Engineering and Life Sciences with a series of subareas respectively in the number of 6 for Social and Humanities Sciences, 10 for Physical Sciences and Engineering and 9 for Life Sciences. The simplification is maximum, therefore after the sub-areas for each of them there are a series of 333 keywords. The application of this classification leads to a specific result of an analytical, deductive and comparative process of the scientific disciplines and group of academic fields of the descriptors with those inherent to the physical activity and sports sciences. Specifically, the areas identify human and social sciences with the initials SH (Social Humanities) and life sciences with the initials LS (Life Science). Following are the respective sub-areas of the 2 Areas with descriptors (area, sub area and keywords) relevant to the physical activity and sports sciences: 1) Social Sciences and Humanities SH3 The Social World, Diversity, Population: Sociology, social psychology, demography, education, communication and SH4 The 
Human Mind and Its Complexity: Cognitive science, psychology, linguistics, philosophy of mind 2) Life Sciences LS4 Physiology, Pathophysiology and Endocrinology: Organ physiology, pathophysiology, endocrinology, metabolism, aging, tumorigenesis, cardiovascular disease, metabolic syndrome as well as LS5 Neurosciences and Neural Disorders: Neurobiology, neuroanatomy, neurophysiology, neurochemistry, neuropharmacology, neuroimaging, systems neuroscience, neurological and psychiatric disorders. The identification of ERC areas and subareas is completely insufficient and incomprehensible to try to establish a scientific relationship because generic and wide where the physical activity and sports sciences dissolve in Group of disciplines and field, therefore requires an additional step that analytically deepens the subareas: the descriptors scientific. Given the complexity of the process, the classification is completely collated as follows.

Table 5. The ERC panel structure keyword

\begin{tabular}{|l|l|}
\hline \multicolumn{2}{|c|}{ KEYWORD ERC PANEL STRUCTURE } \\
\hline SH3_9 & Health, ageing \\
\hline SH3_11 & Social aspects of learning, curriculum studies, educational policies \\
\hline SH3_14 & Science and technology studies \\
\hline SH4_1 & $\begin{array}{l}\text { Cognitive basis of human development and education, developmental disorders; } \\
\text { comparative cognition }\end{array}$ \\
\hline SH4_2 & Personality and social cognition; emotion \\
\hline SH4_3 & Clinical and health psychology \\
\hline SH4_4 & Neuropsychology \\
\hline SH4_5 & Attention, perception, action, consciousness \\
\hline SH4_6 & Learning, memory; cognition in ageing \\
\hline SH4_7 & Reasoning, decision-making; intelligence \\
\hline SH4_8 & Language learning and processing (first and second languages) \\
\hline SH4_9 & Theoretical linguistics; computational linguistics \\
\hline LS4_2 & Comparative physiology and pathophysiology \\
\hline LS4_4 & Fundamental mechanisms underlying ageing \\
\hline LS5_4 & Sensation and perception (e.g. sensory systems, sensory processing, pain) \\
\hline LS5_5 & Neural bases of cognitive processes (e.g. memory, learning, attention) \\
\hline LS7_3 & Other medical technologies for diagnosis and monitoring of diseases \\
\hline LS7_8 & Epidemiology and public health \\
\hline LS7_9 & Environmental health, occupational medicine \\
\hline LS7_10 & Health services, health care research, medical ethics \\
\hline
\end{tabular}




\section{THE PERSPECTIVE OF PHYSICAL ACTIVITY AND SPORTS SCIENCES}

To introduce the perspective of the physical activity and sports sciences as a function of a definitive arrangement of "knowledge", it is useful to grasp the significant elements of the study and to make a synthesis in order to obtain a construction that can be convincing in method and merit. To grasp in the sign of a single declaration of the physical activity and sports sciences, two second approaches can be proceed:

1) Declining the contents of "knowledge" and also the methods of research, if different than the research traditions of the scientific area.

2) Following the document evolution by specifying the type of sources: a) Synthesis of the declaratory of academic disciplines of the physical activity and sports sciences, b) Evolution of the content of group of academic recruitment field and academic recruitment field, (initially the nine competition sectors, then subsequently 06N2 Sciences of the exercise physical and sport and 11D2 Didactics, special pedagogy and educational research (limited to the part pertaining to motor and sports sciences), c) Collation of the CUN key words, first those strictly coherent and then related ones, d) Collation of ERC Panel Structure keywords.

The highest regulatory act of rank with the contents characterizing the scientific identity and which has the most distant backdating is, without a doubt, the law of ISEF Reform which has identified the two new academic disciplines characterizing and for which the CUN it has determined the denotation in Methods and Didactics of the physical activity and sport activities and the connotation in very specific declarations. It is from this document that we must start and the genesis of the scientific identity is the identification of specific topics grouped together and belonging to the Sciences of the physical activity and to the Sciences of the sports disciplines:

a) Theory and methodology of human movement (Schimdt et al, 2018), of the training (Meinel \& Schnabel, 1986, Matveev, 1972, Bompa \& Carrera, 2005) on motor activity for developmental age (Arnold, 1988).

b) Theory, technique and didactic of motor activities (Bernstein, 1967) for the adult and elderly age of the "adapted" motor and sports activity and preventive and compensative motor education (Winnick \& Porretta).

c) Theory, technique and didactic of motor activities and group sports (Teodurescu, 1985), recreational and free time of groups included swimming sports (Bellotti \& Zanon, 2008).

d) Motor assessment methods (Zatsiorsky \& Kraemer, 2016) and aptitudinal in sport (Tomas \& Nelson, 2001).

d) Organization of the sports organisms (De lulis \& Pescante, 2004).

These themes can be replaced by the 10 key words related to the physical activity and sports sciences. As a second moment of synthesis it is advisable to merge the two existing declaratories and summarize one in application of the drastic simplification request. It could be declined with the same literal modality with which the CUN from the birth of the physical activity and sports sciences intended to identify them:

The academic disciplines deals with the development and teaching of theories, techniques and methods for general physical and motor education or aimed at particular groups or age groups and for the training and practice of different sports activities and of the performance evaluations and athletic aptitudes. This declaratory is strictly alleging to the motor and sports sciences excluding the academic disciplines and its "' of the affinities that instead are in the declaratory of the group of academic recruitment field and academic 
recruitment field of Sciences of the physical exercise and sport and in the part of the other one of Didactic, special pedagogy and educational research.

\section{Disciplinary grouping and research domains}

The main issue concerning the full and complete arrangement of "knowledge" with the European scheme is dealt with by the CUN systematically as a result of the mandate received from the Minister of Education, University and Research with the institution in the official nomenclature of disciplinary groupings replacing respectively of academic disciplines, group of academic recruitment field and academic recruitment field and of the corresponding declaratory. In addition, the CUN also proposed the establishment of research domains also related to disciplinary groupings to fully align with the European Classification System in areas, subareas and keywords. The disciplinary groupings may also be of different research areas and may have various profiles so as to simultaneously guarantee the traditional investigative methodology of analysing the detail and at the same time connecting them transversely with other details of other knowledge. They will have a code, a title and their own declaratory. Alongside the system of disciplinary groupings, the CUN, identifies a taxonomy of research domains also transversal to disciplinary areas, to classify research activities in line with that used by the European Research Council. The research domains will be exclusively aimed at describing and managing research activities, in particular as regards the aspects related to the evaluation of research and projects. Each research domain will be articulated in a series of keywords, defined by the CUN and by the other institutional subjects of the university and research systems, which are representative of the cultural specificities of each study community, so that each professor can identify those corresponding to the own research activity and community of reference. In the list of keywords may also include the denominations of the profiles used for the description of the disciplinary groupings and, to further delineate their research activity, a series of four to five keywords may be chosen, of who two to three taken from a set encoded used for the articulation of research domains, and another two-three proposals freely. The teacher will indicate, in accordance with the chosen keywords, his main research domain. However, key words can also belong to different domains, in order to guarantee the possibility of highlighting interdisciplinary research activities. (CUN General Opinion 22, 7/5/2018). For physical activity and sports sciences, this arrangement of groupings and domains allows the same modifying treatment to other academic disciplines, therefore the smallness of the number of university teachers will not weigh negatively as has happened up to now. The ongoing transformation will not take into account the number of structured scholars in university, but will be carried out only on the scientific identity of each academic disciplines and "knowledge".

\section{CONCLUSIONS}

The way to complete alignment with the international scheme of knowledge facilitates the clarification underway for sports motor sciences which, being a young academic disciplines, in Italy is struggling to take off for the obstacles placed by the academic and professional powers (Raiola, 2018). The definitive scientific identity of sports motor sciences in Italy will have to be achieved also following a downsizing of the Italian National Olympic Committee CONI which carries out its role as manager of sports activities from the position of public body, as if it were a real prorpio Ministry of Sport. Of course, research and training are also affected by the action of CONI, which also commits public human and economic resources.

\section{REFERENCES}

Arnold, P. Education, movement and the curriculum. London: Falmer press, 1988.

Bellotti P, Zanon S., Storia del concetto di allenamento. Perugia, Italy: Calzetti Mariucci, 2008 Bellotti P, Zanon S. Storia del movimento umano. Perugia, Italy: Calzetti Mariucci, 2008. 
Bernstein, N.A. The co-ordination and regulation of movements. Oxford: Pergamon Press, 1967. Bompa T, Carrera MC. Periodization training for sports. Champaign, IL: Human Kinetics, 2005.

De Lulis A., Pescante M., Storia dell'educazione fisica e dello sport, Monnier, Roma, 2004.

D'Elia F., Raiola G., (2018) I campionati sportivi studenteschi e la progettazione speciale scolastica nella scuola Primaria, atti Seminario tematico Movimento e sport in ambiente educativo, 20-21 Bressanone (BZ) SIEMeS.

Matveev LP. Periodisierang des sportichen treining. Berlin, Germany: Berles end Wernitz, 1972. Matveev L. Fundamentals of sport training. Moscow, Russia: Fizkultura I Sport, 1977 (translated by Albert P. Zdornykh. Moscow, Russia, 1981).

Gaetano, R. (2012) Motor learning and didactics into physical education and sport documents in middle school-first cycle of education in Italy, Journal of Physical Education and Sport, 12 (2), pp. 157-163.

Meinel G., Schnabel G., Teoria del movimento, Roma , Società stampa sportiva, 1984.

Raiola G., (2018) le SCIENZE MOTORIE e SPORTIVE tra SAPERI ed EUROPEAN RESEARCH COUNCIL. Samnicadum edizioni, Benevento.

Raiola G., (2017) Cenni storici sull'educazione fisica e sportiva, atti $1^{\circ}$ convegno SIEMeS, Enna.

Raiola, G., (2012) La complessità dello studio in ambito educativo sportivo, Pensa Multimedia, Lecce, Teodurescu L., Teoria e metodologia degli sport di squadra, Società Stampa Sportiva,1985.

Tomas, J.R., Nelson J.KResearch method in physical activity (3th edition) Champaign IL USA., 2001 Tomas, J.R., Nelson J.K., Silverman S. J., Research method in physical activity (4th edition) Champaign IL USA, 2005.

Schmidt, R, Lee T., Winstein, C., Wulf, G., Zelaznik, H., Motor control and learning, Human Kinetics, IL Champaign, USA, 2018.

Winnick J., Porretta D, (2006) Adapted-Physical-Education-and-Sport-6th-Edition, Human Kinetics IL Champaign, 2016 Zatsiorsky, VM, Kraemer, WJ. Science and practice of strength training. Second Edition. Champaign IL: Human Kinetics.

\section{Documents}

Attachment Ministerial Decree 855, 30 October 2015, Italy

European Research Council Panel Structure (2018) https://erc.europa.eu/sites/default/files/document/file/ERC_Panel_structure_2018.pdf

Law n. 18, 16 gennaio 2006, Riordino del Consiglio Universitario Nazionale.

InformaCUN 225 of 21-23 March 2018.

Law n. 88, 7 febbraio 1958 Istituzione degli Istituti Superiori di Educazione Fisica.

Law n. 16, 16 January 2006,Riordino del Consiglio universitario nazionale.

Legislative decree 178, 8 maggio, 1998, Trasformazione degli Istituti Superiori di educazione Fisica e Istituzione della facoltà di scienze motorie e delcorso di diploma e di laurea di scienze motorie.

Ministerial Decree n. 855, 30 October 2015, Italy.

Ministerial Decree n. 366, 29 July, 2011, Italy.

Law 11 n. 114, 10 agosto 2014, Conversione in legge, con modificazioni, del decreto-legge 24 giugno 2014 , n. 90 , recante misure urgenti per la semplificazione e la trasparenza amministrativa e per l'efficienza degli uffici giudiziari.

Legislative decree 8 n. 178 (1998) 8 giugno1998, Trasformazione degli istituti superiori di educazione fisica e istituzione della facolta' e del corso di diploma e di laurea in scienze motorie. 
